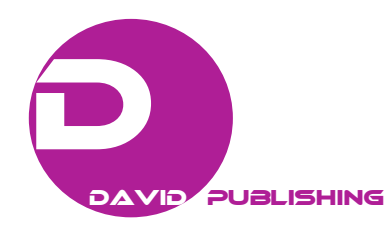

\title{
Cluster of Strong Earthquakes and Aftershocks in Ahar-Varzeghan Area on August 11, 2012
}

\author{
Ebad Ghanbari, Ahmadi Mashinchi Arash and Valizadeghan Arjmand Sadegh \\ Department of Civil Engineering, Islamic Azad University, Jolfa International Branch, Jolfa 54417-33574, Iran
}

\begin{abstract}
Seismic events are very complex spatial-temporal phenomena. Seismic catalogues, reporting information about spatial-temporal distribution of the main shocks, are nowadays available for many seismic areas in the world, very often major events mark the beginning of a series of earthquakes (aftershocks) whose frequency and energy are meanly decreasing in time down to the background level of activity. Azerbaijan is one of the most active segments of the Alpine-Himalayan seismic belt and marks the junction between the African-Arabian and Indian plate to the south, and Eurasian plate to the north. The cluster of earthquakes that struck near Varzeghan-Ahar was centered near the Gosha-Dagh fault, but preliminary data suggested that the fault was not responsible for the temblor. On the late afternoon of Saturday, August 11, 2012, the northwest of Iran was shaken by two of the strong earthquakes in Iranian history. First was hit by $M_{W}$ (moment magnitude scale) $=6.4$ Richter at local time 16:54 (12:23 GMT (Greenwich Mean Time)), and about $11 \mathrm{~min}$ later, an $M_{W}=6.3$ struck $10 \mathrm{~km}$ to the west. The spatial-temporal clustering of micro earthquakes (aftershocks) near Varzeghan, is parameterized by means of a generalized passion model. The region has known faults but numerous smaller or deeply buried faults remain undated, according to the Geological Survey of Iran.
\end{abstract}

Key words: Ahar-Varzeghan, cluster of strong earthquakes, aftershocks, strike-slip fault.

\section{Introduction}

Earthquakes occur in narrow belts or on active faults. The region between the Black Sea and the Caspian Sea is part of the central Asian segment of Alpine-Himalaya fold belt. The mountain ranges of the Caucasus (Azerbaijan, Armenia, Georgia and other areas) were formed by the collision of African-Arabian and Indian tectonic plates, the Eurasian plate [1]. Azerbaijan has a high density of Pliocene-Quaternary faults and frequent destructive earthquakes which activates some existing faults on the surface. The Varzeghan-Ahar region has never seen a quake that big, which covers parts of Azerbaijan.

Earthquake clustering occurs on many different scales. The intensify of seismic ground motion is a function of earthquake magnitude and distance from the seismic source, as well as local soil conditions, topography and geological and tectonically conditions.

Corresponding author: Ebad Ghanbari, professor, research fields: earthquake engineering and geotechnics. E-mail: e.ghanbari@tabrizu.ac.ir.
Locally, earthquake clustering in time and space is recognized as aftershocks activity that follows a main shock earthquake, on August 11, 2012, tow seismic sequences, characterized by main shocks with ML (local magnitude) 6.4 and 6.3, respectively, occurred in the Ahar-Varzeghan region area. The regional seismic network of NW of Iran has recorded more than 1,800 2,000 aftershocks until September 20, 2012. The improved locations showed that the seismic activity is mainly arranged along a NE-SW oriented volume, at a depth range of $9 \sim 18 \mathrm{~km}$, involving the basement sedimentary and crystalline units. This orientation is confirmed by the analysis of the local mechanism. Most focal solutions show strike-slip component with one of the nodal planes consistent with the main orientation of the seismic events. Among the records of aftershocks, observation of the August 11, 2012, $M_{w}=6.4, M_{w}=6.3$, very similar waveforms from clusters of small earthquakes were found. Cross-correlation of the waveform of each pair in the cluster confirmed the similarities. Moderately, damaging earthquakes strike the region every decade 
or two, and smaller earthquakes are felt about once or twice a year. The largest historical earthquake in the region, about 150 200 years ago, have not been seen [2].

\section{Geological Setting}

The Ahar-Varzeghan earthquake clusters of August 11, 2012, occurred in the low plateau region of northeast of Tabriz City. Geological setting of the area consists of sedimentary, volcanic sedimentary, platonic and volcanic, and terrestrial deposits embracing almost entire stratigraphic range beginning from early Mesozoic through Quaternary time. The Ahar-Varzeghan area is about $1,800 \mathrm{~m}$ above sea level and located between two NW-SE trending mountain mugs.

To the north, the Sungun-Shivarh Mountain with an elevation of 2,652 m represents the highest summit among the many mountains in the north and the surrounding of Ahar-Varzeghan area.

In order to improve the existing data about the geological conditions, a complementary program of site investigation has been arranged in Ahar-Varzeghan and its vicinity by geological survey of Iran. On the late afternoon of Saturday, August 11, 2012, two of the strong earthquakes shook the NW of Iran in Iranian history. First was hit by $M_{w}=6.4$ at 16:54 local time (12:23 GMT (Greenwich Mean Time)), and about 11 min later an $M_{w}=6.3$ struck $10 \mathrm{~km}$ to the west. The spatial-temporal clustering of micro earthquakes (aftershocks) near Varzeghan, is parameterized by means of a generalized poison model [3]. A "cluster" is defined empirically with the criteria that: (1) occurrence times of shocks are within $10 \mathrm{~min}$ to $15 \mathrm{~min}$ of each other; and (2) focal separation is less than several hundred meters (until September 20, 2012, more than 2,000 aftershocks have occurred in this area). Regarding the sequences, the analyzed data are relative to Azerbaijan area, where we have knowledge of the tectonic setting of the area and their seismic history.
The two main earthquakes occurred as a result of oblique strike-slip faulting in the shallow crust of the Eurasian plate, approximately $300 \mathrm{~km}$ east of the plate boundary between the Eurasia and Arabian plates [4]. Trends of the maximum premarital compressive stress of are scattered, ranging from NNW-SSE to NE-SW.

Many faults have been recognized in the region, from after strong earthquake occurred in August 2012 in this area. Through analysis of high-quality broadband wave form data from this earthquake, it determined that the earthquake occurred at depth of $10 \mathrm{~km}$ in low ground level continental regions by combining this location with more than 2,000 aftershocks from August 11 to September 12, 2012, which occurred at $10 \mathrm{~km}$ to $15 \mathrm{~km}$ depth.

The Varzeghan-Ahar earthquake was a complex earthquake, and the paleo seismological data show that, for the same regions, prior earthquakes have occurred in dusters of ruptures of several faults separated long quiescent periods $[5,6]$.

Several examples have been chosen that illustrate various aspects of the phase locking of faults. These are from a variety of tectonic settings: normal faulting in between Tabriz-Zanjan Highway, strike-slip faulting in the Tabriz region of northern Tabriz City $(\mathrm{NTF}=$ north Tabriz fault), and other major and small faults.

The most well-known example is a cluster of earthquake that occurred in the Tabriz region of central Azerbaijan in 1780.

In order to improve the existing data about the geological conditions, a complementary program of site investigation has been arranged in Varzeghan-Ahar and its vicinity by Geological Survey of Iran. Based on the results of these investigations and the previous available data, six different lithologies have been characterized at the area including: (1) recent and late Quaternary alluvium; (2) Paleogene (submarine volcanic rocks); (3) sedimentary rocks; (4) violet conglomerate and breccias; (5) sandstone; (6) intrusive igneous rocks 
(micromonzonite related trachyandesite). Most parts by the region of Varzeghan-Ahar have been constructed on Quaternary alluvial. The state of stress on a fault is a key factor used to determine if rupture is imminent.

A common view is that once the earthquake has occurred and the released stress on a fault will remain quiet until stresses in the earth's crust have time to rebuild, typically over hundreds thousands of years. Probabilistic earthquake catastrophe models follow this concept, which is known as the seismic cycle (Fig. 1).

The mean return period $\mu$ depends on the long-term rate of tectonic stress loading $\frac{\delta \sigma_{t}}{\delta t} \quad(\delta$ : change of any changeable quantity; $\sigma_{t}$ : stress per time; $\delta_{t}$ : change of time), which is usually assumed constant, the failure stress $\sigma_{f}$ and the earthquake stress drop $\Delta \sigma_{o}$.

\section{Active Tectonics}

The active faults of Iran result from active crustal deformation due to the on-going continental convergence between African-Arabian and Eurasian plates. Earthquake focal mechanisms suggest that this convergence has been accommodated mainly through NNW trending right-lateral strike-slip faults in north-western Iran. These strike-slip faults consist of several discontinuous faults segments, which are averaged, in an en-echelon pattern. Two models are used to analyze the active crustal deformation in

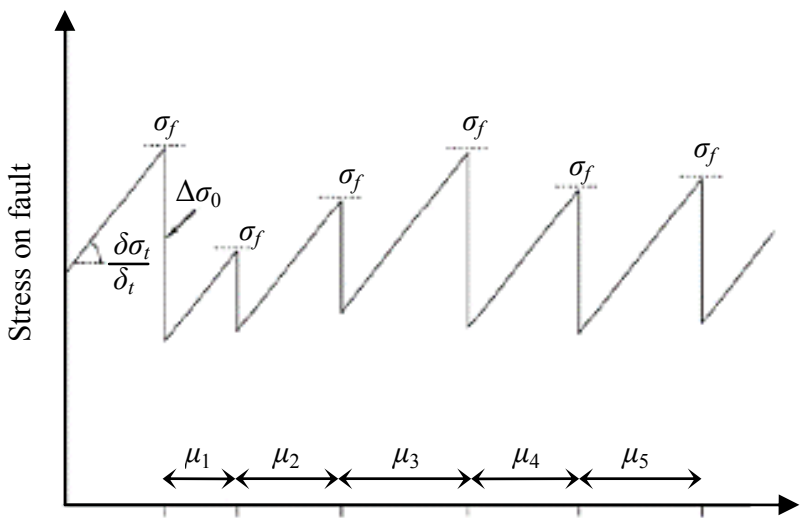

Fig. 1 The seismic cycle, in which the stress on a fault increases due to tectonic loading. continental convergent zones. The first model is the rigid plate model which describes faulting in terms of relative motion of several rigid plates [7]. The second model assumes a continuous deformation throughout the continental crust with some concentration along the major active faults.

Some of these segments ruptured during several earthquakes: along the north Tabriz fault zone in 634, 1527, 1641, 1721, 1780, 2007, 2008, and along the Gosha-Dagh and Ujan (Bostanabad) fault in 1971, 1974, 1975, 2000, 2004, 2008 and 2012. The Varzeghan buried fault that activated lately, however, has been seismically unknown during the last 200 300 years, and seismic evidence shows reactivation of a buried fault in the Azerbaijan slab by the August 11, 2012 Varzeghan-Ahar earthquake.

Azerbaijan is located on the boundary between Eurasian plate and African-Arabian plates. As result of the continuous stress and collision, Azerbaijan is densely faulted. Therefore, one of the major tasks for disaster mitigation is to delineate the distribution of active faults. Active faults exposed at the surface are generally expressed by escarpment on topography, however, most of the faults are shallowly buried, making them difficult to locate and map.

Many faults have been recognized in the region, including the BBF (Baja-baj fault) and the GDF (Gosha-dagh fault) and the CF (ChoBanlar fault) as shown in Fig. 2.

A fundamental problem is structural geology and rock mechanics for understanding the nucleation, growth and interaction of faults with fault networks in

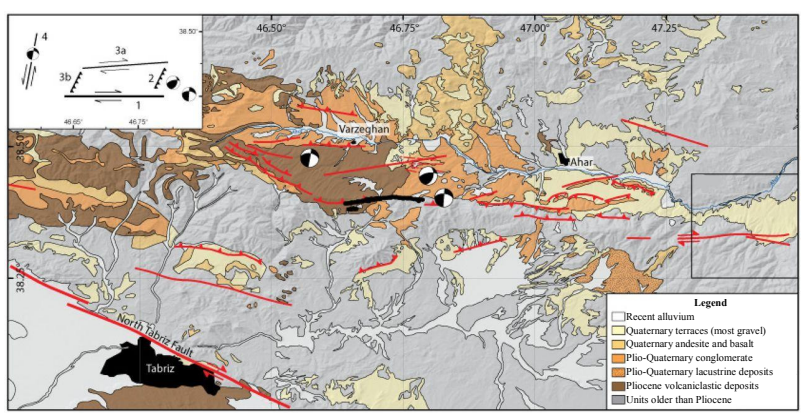

Fig. 2 The strike-slip fault and clustering of earthquakes (August 11, 2012) Ahar-Varzeghan area. 
broad zone under simple shear stress that such phenomenon has been seen in new earthquakes.

This understanding can give us the knowledge about the tectonic evolution of the crust, earthquake mechanism basin development underground fluid flow system and the engineering properties of rock mass. Field geological investigation has found steps, pull-apart basin and up wraps strike strip faults, which indicate fault interaction in the study area.

The distribution, extension and characteristics of these faults are not clear at present because only very few surface of those faults can be precisely examined that few major faults can be recognized from after strong earthquake occurred in August 11, 2012, in this area. The processing of these data can provide important evidence for regional-scale basement faulting in southern Varzeghan and thus for understanding the framework of the region. The principal subjects of this study are demarcating the buried faults and to identify the important trends in the magnetic anomaly filed [8].

"Through analysis of high-quality broadband, waveform data from the August 11, 2012 earthquake determined that the earthquakes occurred at the depth of 9.7 9.9 km below ground level, deeper than most earthquakes in interplate continental regions." By combining this location with more than 3,000 aftershocks, until August 11 to September 15, 2012, which occurred at $10 \mathrm{~km}$ to $15 \mathrm{~km}$ depth. Ghanbari's [9] research shows direct relation earthquakes with one of the known faults of the Varzeghan-Ahar area. His investigation suggests that the strike-slip fault on this Bajabaj village was happening on the near vertical fault plane at $10 \sim 12 \mathrm{~km}$ depth, which indicates the ancient buried faults associated with a possible early Mesozoic system are being reactivated by contemporary compressive stress.

\section{Analysis of Aftershocks}

Earthquake clustering occurs on many different scales. Locally, earthquake clustering in time and space is recognized as aftershock activity that follows a main shock earthquake. Other observations of earthquake clustering primarily relate to spatial proximity, irrespective of the temporal aspects of occurrence.

This paper focuses on earthquakes that cluster both spatially and temporally. Aftershocks are the most recognizable of these earthquakes which are defined by magnitude of how it is related with the main shock, their effects on the built environment can be even more than the main shock, which is depended to their proximity to populations centers, their depth of occurrence and their rupture mechanism.

The focal depths of the first and second main shocks were determined $9.9 \mathrm{~km}$ and $18 \mathrm{~km}$, respectively. According to Fig. 1, the focal mechanism of both events is consistent with right-lateral strike-slip faulting on EW trending fault parallel to aftershocks sequence and south Ahar fault (Fig. 3)

The second main shock $\left(M_{w}=6.3\right)$ shows a considerably reverse component [11]. More than 3,000 events were recorded during the 40 days (August 11 to September 20, 2012) duration of the experiment that the primary results of analysis show more than 600 aftershocks, recorded first week after the main shock. The strongest acceleration PGA (peak ground acceleration) of the first and the second

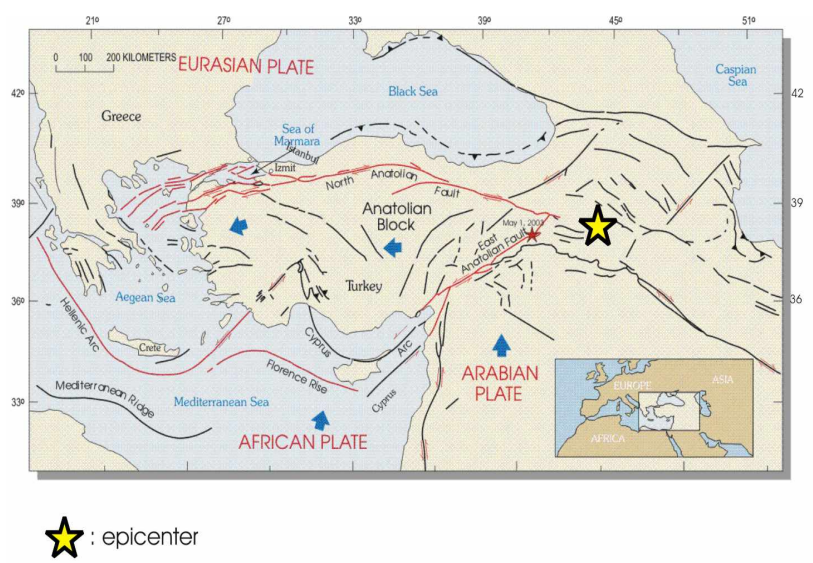

Fig. 3 Distribution of active faults in the NW of Iran and Anatolian region. Modified from Barka and Reilinger [10]. 

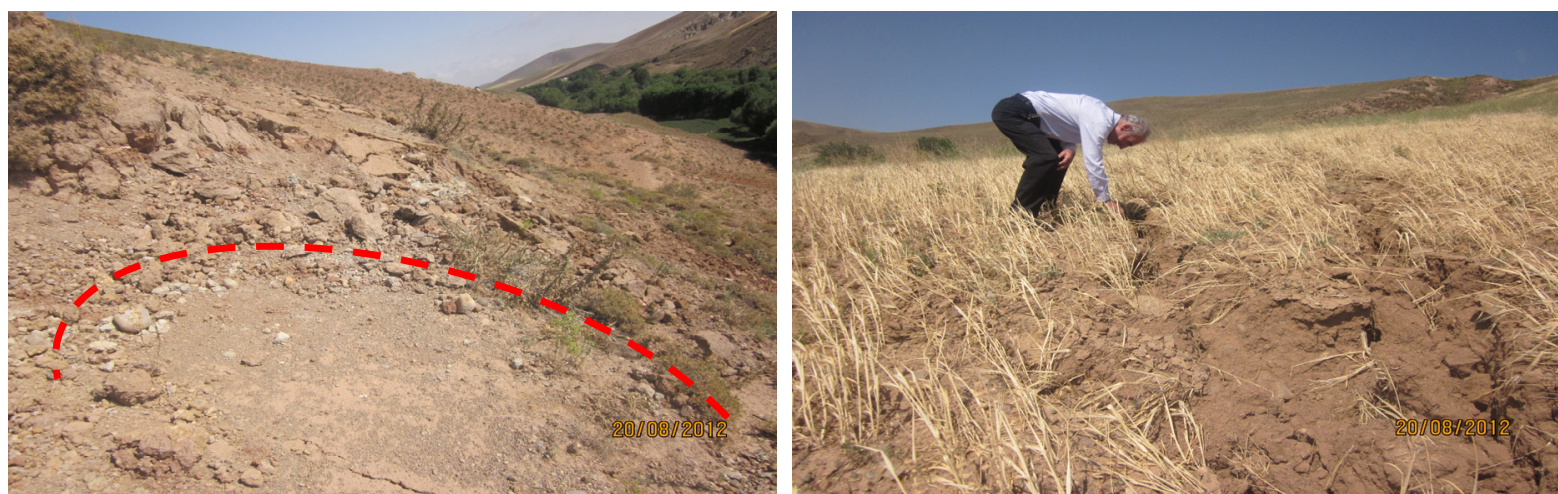

Fig. 4 The failure of earthquake triggered landslide, near the hill (Arpa Zami) at the Chakhmakhbulagh village,Varzeghan area.

earthquakes were $0.427 \mathrm{~g}$ and $0.534 \mathrm{~g}$, respectively, recorded at Varzeghan station.

The first event $(M=6.4)$ of the Azerbaijan earthquakes was recorded by 57 stations, which was ranged from $15 \mathrm{~km}$ up to more than $198 \mathrm{~km}$ and the second event $(M=6.3)$ occurred 12:34:35 which was recorded by 35 stations.

Until September 20, 2012, more than 3,000 aftershocks have occurred in the region that more than 150 had magnitude larger than 3. The clearest evidence of the earthquake clustering was found in aftershock that the sequences followed the main shock of an earthquake.

Although patterns are more readily observed in the aftershock sequences of one event, separate earthquakes can also occur in clusters. For instance, Ahar-Varzeghan's 6.4 magnitude, first progressive quakes along the Varzeghan-Ahar buried fault in Azerbaijan triggered two large earthquakes, and about 11 min later, a 6.3 magnitude struck $10 \mathrm{~km}$ to the west [12]. This example of clustering demonstrates that large earthquakes can trigger additional earthquakes, ranging from aftershocks in the immediate vicinity to remote earthquakes hundreds of miles away. Scientists can calculate where and how the stress has been changed after the main shock, and this information can be used to increase the predictability of the aftershock sequence and the next main shock. Aftershocks are abundant on the southern section of the fault, Baja-Baj was the spot where the stress has increased. However, on the western section, it is relatively quiet.

\section{Landslide and Rockfall}

Earthquakes are a major cause of landslides and rockfalls which are in turn a major contributor to the damage and causalities associated with earthquakes. Based on the spatial distribution of landslide and rockfall and ground strong motion induced during the Varzeghan-Ahar earthquakes, the relationship between them and earthquakes was explored. Several landslides and rockfalls occurred in the distinct area are shown in Fig. 4. Most of the this phenomenon observed happened in Chal-Dagh (west of Chal-Dagh, Fig. 4).

\section{Conclusions}

This paper focuses on earthquakes that cluster both spatially and temporally. Aftershocks are the most recognizable of these earthquakes which are definite by magnitude of how it is related to the main shock, and their effects on the built environment can be even more than the main shock, which is dependent to their proximity to population centers, their depth of occurrence, and their rupture mechanism. The Varzeghan-Ahar area formed during the early Mesozoic by reactivation of African-Arabian dextral ductile shear zones in the basement. These shear zones 
are of two families, longer ones trending NW-SE (Sungun to Sheevardagh) and shorter ones trending W-E (Aytakhti-Dagh to Oglandagh) that this region covers part of Azerbaijan. Most parts by the region of Varzeghan-Ahar have been constructed on Quaternary alluvial. The state of stress on a fault is a key factor used to determine if rupture is imminent.

The region has known faults but numerous smaller or deeply buried faults remain undated, according to the Geological Survey of Iran. Evidence from seismological studies suggest that the style of faulting changes with depth due to variations in confining pressure along natural fault zones in the upper depths $<3 \mathrm{~km}$, and deformation along faults with well developed gauge zones that does not involve large stress drops is aseismic.

At greater burial, for example, Ahar-Varzeghan buried fault depth $>3 \mathrm{~km}$ where higher confining pressures exist, the folding is usually associated with large stress drops and earthquakes.

Active faults exposed at the surface are generally expressed by escarpment on topography, however, most of the faults are shallowly buried, making them different to locate and map.

\section{References}

[1] Nemcok, M. A., Feyzupayev, A., Kadirov, F. A., Zeynalov, G. A., Allen, R., Christensen, C., and Welkev, B. 2011. "Neotectonics of the Coulasus and Kuravallex Azerbajan." Global Engineers and Technologist Review 7 (1): 96-102.

[2] Vecchio, A., Carbone, V., Serriso, L., Derose, C., Guerra, I., and Harubaghia, P. 2008. "Statistical Properties of Earthquakes Clustering." Nonlinear Processes in Geophysics 15: 333-8.

[3] Thenhaus, P. C., Campbell, K. W., and Khater, M. M. 2012. Spatial and Temporal Earthquake Clustering: Part
2 Earthquake Aftershocks: An Overview Of Eqecat's Perspective. New York: Guy Carpenter \& Company, LLC.

[4] Wada, K., and Goto, H. 2011. "Generation Mechanism of Surface and Buried Faults. Effect of Plasticity in shallow Crust structure." Bulletin of the Seismological Society of America 102 (4): 1712-28.

[5] Ghanbari, E. 2005. "Puleoseismicity and New Seismicity Studies in Azerbaijan Area and the Necessity of Microseismic Zonation in Tabriz City and Other Siesmic Regions of Azerbaijan." Presented at the Second International Conference on Urban Earthquake. Engineering, Tokyo, Japan.

[6] Ghanbari, E. 2009. "Paleo and New Earthquakes and Evaluation of North Tabriz Fault (NTF) Displacement in Relation to Recurrence interval of destructive Earthquakes." Presented at 2000 ANCER Workshop, Illinois.

[7] Mckenzie, D. 2007. "Active Tectonics of the Mediterranean Region." Geophysical Journal International 30 (2): 109-85.

[8] Fu, C., Yang, T. F., Walia, V., and Chen, C. 2005. "Reconnaissance of Soil Gas Composition over The Buried Fault and Fracture Zone in Southern Taiwan." Geochemical Journal 39: 427-39.

[9] Ghanbari, E. 2006. "Comparison of Mechanism and Operation of North Tabriz Fault (NTF) and North Anatolian Fault (NAF) with Mechanism of San Andreas Fault (SAF) in California (USA)." Presented at the 100th Anniversary 1906 Earthquake Conference, San Francisco.

[10] Baraka, A., and Reilinger, R. 1997. "Active Tectonics of the Eastern Mediterranean Region: Deduced from GPS, Neotectonics and Seismicity Data." Annali Di Geofisica 40 (3): 589-610.

[11] Razzaghi, M. S., and Ashtiani, M. G. 2012. A Preliminary Reconnaissance Report on August 11th 2012, Varzeghan-Ahar Twin Earthquakes in NW of Iran. International Association of Seismology and Physics of the Earth's Interior.

[12] Scholz, C. H. 2010. "Large Earthquake Triggering Clustering and the Synchronization of Faults." Bulletin of the Seismological Society of America 100 (3): 105-13. 